\title{
Lactate Metabolism and Microbiome Composition Are Affected by Nitrogen Gas Supply in Continuous Lactate-Based Chain Elongation
}

\author{
Carlos A. Contreras-Dávila, Arielle Ali, Cees J. N. Buisman and David P. B. T. B. Strik *D
}

Citation: Contreras-Dávila, C.A.; Ali, A.; Buisman, C.J.N.; Strik, D.P.B.T.B.

Lactate Metabolism and Microbiome Composition Are Affected by Nitrogen Gas Supply in Continuous Lactate-Based Chain Elongation. Fermentation 2021, 7, 41. https:// doi.org/10.3390/fermentation7010041

Academic Editor: Stefania Costa

Received: 2 March 2021

Accepted: 17 March 2021

Published: 20 March 2021

Publisher's Note: MDPI stays neutral with regard to jurisdictional claims in published maps and institutional affiliations.

Copyright: (c) 2021 by the authors. Licensee MDPI, Basel, Switzerland. This article is an open access article distributed under the terms and conditions of the Creative Commons Attribution (CC BY) license (https:/ / creativecommons.org/licenses/by/ $4.0 /)$.
Environmental Technology, Wageningen University \& Research, Bornse Weilanden 9, 6708 WG Wageningen, The Netherlands; carlos.contrerasdavila@wur.nl (C.A.C.-D.); arielle.ali@live.com (A.A.); cees.buisman@wur.nl (C.J.N.B.)

* Correspondence: david.strik@wur.nl

Abstract: Chain elongation reactor microbiomes produce valuable medium-chain carboxylates (MCC) from non-sterile residual substrates where lactate is a relevant intermediate. Gas supply has been shown to impact chain elongation performance. In the present study, the effect of nitrogen gas $\left(\mathrm{N}_{2}\right)$ supply on lactate metabolism, conversion rates, biomass growth, and microbiome composition was evaluated in a lactate-fed upflow anaerobic reactor with continuous or intermittent $\mathrm{N}_{2}$ gas supply. Successful MCC production was achieved with continuous $\mathrm{N}_{2}$ gas supply at low superficial gas velocities (SGV) of $0.22 \mathrm{~m} \cdot \mathrm{h}^{-1}$. Supplying $\mathrm{N}_{2}$ at high SGV $\left(>2 \mathrm{~m} \cdot \mathrm{h}^{-1}\right)$ either continuously $\left(2.2 \mathrm{~m} \cdot \mathrm{h}^{-1}\right)$ or intermittently $\left(3.6 \mathrm{~m} \cdot \mathrm{h}^{-1}\right)$ disrupted chain elongation, resulting in production of short-chain carboxylates (SCC), i.e., acetate, propionate, and n-butyrate. Caproiciproducens-dominated chain-elongating microbiomes enriched at low SGV were washed out at high SGV where Clostridium tyrobutyricum-dominated microbiomes thrived, by displaying higher lactate consumption rates. Suspended growth seemed to be dominant regardless of SGV and gas supply regime applied with no measurable sludge bed formed. The highest MCC production from lactate of $10 \mathrm{~g} \mathrm{COD} \cdot \mathrm{L}^{-1} \cdot \mathrm{d}^{-1}$ with electron selectivities of $72 \pm 5 \%$ was obtained without $\mathrm{N}_{2}$ gas supply at a hydraulic retention time (HRT) of 1 day. The addition of $5 \mathrm{~g} \cdot \mathrm{L}^{-1}$ of propionate did not inhibit chain elongation, but rather boosted lactate conversion rates towards MCC with n-heptylate reaching $1.8 \mathrm{~g} \mathrm{COD} \cdot \mathrm{L}^{-1} \cdot \mathrm{d}^{-1} \cdot \mathrm{N}_{2}$ gas supply can be used for mixing purposes and to steer lactate metabolism to MCC or SCC production.

Keywords: microbial chain elongation; medium-chain carboxylates; lactate; n-caproate; n-heptylate; n-caprylate; Caproiciproducens; Clostridium tyrobutyricum

\section{Introduction}

Chain elongation reactor microbiomes produce valuable medium-chain carboxylates (MCC) from non-sterile residual substrates. MCC are saturated monocarboxylic acids with 6 to 12 carbon atoms that find applications in lubricants, bioplastics, antimicrobials, feed additives, and biofuels production [1]. For bioplastics, MCC can be used in a second bioprocess to accumulate medium-chain length polyhydroxyalkanoates in bacteria such as Pseudomonas putida [2]. Chain-elongating microbiomes utilize energy-rich substrates, e.g., ethanol, lactate, and glucose, as electron donors to elongate short-chain carboxylates (SCC, 1-5 carbon units) to MCC through a series of biochemical condensation and reduction reactions in the reverse- $\beta$-oxidation (RBO) pathway [1]. Electron donors are oxidized to provide electrons (e.g., NADH) and acetyl-CoA for the RBO pathway where two acetylCoA are elongated to even-chain carboxylates, e.g., n-butyrate (nC4), n-caproate (nC6), or $\mathrm{n}$-caprylate (nC8). Lactate is an interesting electron donor that can be easily obtained from residual biomass materials [3-5] and has been successfully converted to n-caproate [4,6-8]. Alternatively, reactor microbiomes may convert lactate to propionate and acetate [9]. Propionate can be activated to propionyl-CoA and enter the RBO pathway [10] to be elongated 
with additional lactate to odd-chain elongated carboxylates such as n-valerate (nC5) and n-heptanoate (nC7).

There is an increasing interest in lactate-based chain elongation processes as lactate seems to be an important intermediate during the conversion of residual heterogenous materials into MCC $[4,11]$. However, lactate conversion rates and selectivities towards MCC remain relatively low. Previous studies using lactate as a model substrate showed n-caproate selectivities below $45 \%$ with production rates reaching $2.3 \mathrm{~g} \mathrm{COD} \cdot \mathrm{L}^{-1} \cdot \mathrm{d}^{-1}$ in a continuous stirred tank reactor (CSTR) [6] and $6.9 \mathrm{~g} \mathrm{COD} \cdot \mathrm{L}^{-1} \cdot \mathrm{d}^{-1}$ in an anaerobic filter [8]. Chain elongation performance may be improved through, for instance, gas supply. The $\mathrm{CO}_{2}$ loading rate has been shown to control chain elongation rates and ethanol conversion efficiency in continuous ethanol-based chain elongation [12]. Hydrogen addition increases MCC production in incubations with ethanol and acetate [13] and lactate [14]. However, high $\mathrm{P}_{\mathrm{H} 2}$ may slow down MCC production rates by affecting energy metabolism in chainelongating bacteria such as Clostridium kluyveri as explained by Angenent et al. (2016). Thus, nitrogen gas $\left(\mathrm{N}_{2}\right)$ may be supplied to avoid inhibition by high $\mathrm{P}_{\mathrm{H} 2} . \mathrm{N}_{2}$ may also be supplied to improve mixing and, subsequently, fermentation in full-scale reactors [15] as it is also done in full-scale ethanol-based chain elongation processes [16]. However, the effect of $\mathrm{N}_{2}$ gas supply at different rates in chain elongation performance has not been reported yet.

Additionally, gas supply may create hydrodynamic shear force and induce the formation of granular sludge or biofilm which would help to increase biomass concentrations. Hydrodynamic shear force applied through continuous gas supply increased granulation rates and sludge properties in anaerobic [17] and aerobic [18] granular sludge reactors. Granulation has been reported to occur in an ethanol-based chain elongation process [19] and granular sludge reactors converting complex waste streams such as thin stillage have achieved MCC production rates around $30 \mathrm{~g} C O D \cdot \mathrm{L}^{-1} \cdot \mathrm{d}^{-1}[11,20]$. However, the presence of several other substrates and nutrients in the complex wastes may have contributed to granulation [21,22] and MCC production.

As well as gas supply, the addition of SCC serving as electron acceptors is one other option to increase chain elongation rates as has been shown in pure culture incubations with lactate and sucrose [23]. Reactor microbiomes also show sluggish ethanol-based chain elongation rates in the absence of acetate as electron acceptor [24]. The authors explained that ethanol conversion to MCC without an electron acceptor may be less energetically favorable and could also result in high hydrogen formation inhibiting conversion rates.

The present study aimed to evaluate the effects of $\mathrm{N}_{2}$ gas supply on lactate metabolism and conversion rates during continuous lactate-based chain elongation. Different volumetric flows and superficial gas velocities were applied through continuous or intermittent gas supply in an upflow anaerobic reactor fed with lactate and operated at pH 5.5 and hydraulic retention time (HRT) of 1-2 days. Since MCC production rates remained moderate, propionate was added as an electron acceptor as an alternative way to increase chain elongation rates. Lactate conversion rate, product spectrum, biomass concentration, and microbiome composition were studied.

\section{Materials and Methods}

\subsection{Substrate, Mineral Medium, and Inoculum}

L-lactate (50\% sodium-(S)-lactate, Merck) was used as electron donor at a constant concentration of $40 \mathrm{~g} \cdot \mathrm{L}^{-1}$. Mineral medium and vitamins were added as described elsewhere [19] and trace elements were prepared after Zhu et al. (2015) [7]. Additionally, $1 \mathrm{~g} \cdot \mathrm{L}^{-1}$ of yeast extract (Merck, for microbiology) and $4 \mathrm{~g} \cdot \mathrm{L}^{-1}$ of tryptone (Sigma-Aldrich, microbiologically tested, $\mathrm{N}$ content $11-16 \%$ ) were added. The feeding solution containing lactate, minerals, and nutrients was adjusted to $\mathrm{pH} 5.5$ with $6 \mathrm{M} \mathrm{HCl}$. The inoculum was obtained from several sources including reactor microbiomes from ethanol-based chain elongation [25] and food waste fermentation [4]. These reactor microbiomes were mixed with uncharacterized microbiomes from unfiltered Chinese liquor; rumen fluid; a 
full-scale lipid-degrading anaerobic digestor; and lab-scale acetate-oxidizing bioanode and biocathode producing n-butyrate. Equal volumes of each source culture were centrifuged separately at $4000 \mathrm{rpm}$ and $20^{\circ} \mathrm{C}$ for $10 \mathrm{~min}$. The supernatant was removed, and the pellet resuspended in oxygen-free demi-water. The resuspensions were then combined to get the inoculum, and $20 \mathrm{~mL}$ of the inoculum was injected into the reactor.

\subsection{Reactor Setup and Operation}

The reactor used was a double-walled glass upflow anaerobic reactor consisting of a vertical column $\left(D_{\text {in }}=6.5 \mathrm{~cm}\right.$; length $\left.=62 \mathrm{~cm}\right)$, a settler $(1.1 \mathrm{~L})$, an inverted funnel for solidgas-liquid separation and a recirculation line (Figure S1) for a total working volume of 3.2 L. The fermentation broth was recirculated from the top to the bottom of the reactor where it mixed with the feeding solution before flowing upwards into the reactor. Two two-neck glass tubes were connected in the recirculation line for $\mathrm{pH}$ control and redox measurements. An $\mathrm{N}_{2}$ gas connection branched into the recirculation for gas supply. Effluent overflowed at the top of the reactor and was collected in a reservoir. Headspace overpressure was controlled $<0.1$ bar with a pressure meter and a vacuum pump. When pressure reached 0.1 bar, gas was pumped from the headspace towards the gas flow meter (drum-type gas meter, Ritter). Temperature was controlled at $30^{\circ} \mathrm{C}$ using a water bath.

The reactor was filled with the feeding solution at $\mathrm{pH} 5.5$, bubbled with $\mathrm{N}_{2}$ gas for $15 \mathrm{~min}$ and inoculated. The reactor was first operated in batch mode with $\mathrm{pH}$ control switched off and a liquid recirculation rate of $9.96 \mathrm{~L} \cdot \mathrm{h}^{-1}$ equivalent to an upward liquid velocity (ULV) of $3 \mathrm{~m} \cdot \mathrm{h}^{-1}$. Continuous operation (Table 1 ) was started at an HRT of 2 days once gas production and $\mathrm{pH}$ increase were observed (7 days). Automatic addition of $2 \mathrm{M} \mathrm{HCl}$ was used to keep a $\mathrm{pH}$ of 5.5 throughout operation. Once n-caproate production became dominant, $\mathrm{N}_{2}$ gas was supplied either continuously or intermittently. Continuous gas flow was supplied at $12 \mathrm{~mL} \cdot \mathrm{min}^{-1}$ in phase 1 , resulting in a superficial gas velocity (SGV) of $0.22 \mathrm{~m} \cdot \mathrm{h}^{-1}$ from day 59.7 . For phase 2 , gas supply was increased to $120 \mathrm{~mL} \cdot \mathrm{min}^{-1}$ $\left(\mathrm{SGV}=2.2 \mathrm{~m} \cdot \mathrm{h}^{-1}\right)$ on day 85.7. Due to the loss of $\mathrm{n}$-caproate production in this phase, gas supply was decreased to $11.3 \mathrm{~mL} \cdot \mathrm{min}^{-1}$ in phase 3 and changed to intermittent addition (days 104.8-149.9). Intermittent gas was supplied at $3.33 \mathrm{~mL} \cdot \mathrm{s}^{-1}$ for $20 \mathrm{~s}$ followed by $5 \mathrm{~min}$ of no gas addition equivalent to SGV of $3.6 \mathrm{~m} \cdot \mathrm{h}^{-1}$ during moments of gas supply. For phase 4 (days 154-188.8), gas was still added intermittently but HRT was shortened to 1 day. Gas supply was stopped in phase 5 (days 197.7-231.9) and recirculation rate was increased (day 195.7) to $29.9 \mathrm{~L} \cdot \mathrm{h}^{-1}\left(\mathrm{ULV}=9 \mathrm{~m} \cdot \mathrm{h}^{-1}\right)$, maintaining these conditions for the rest of the operation time. Lastly, propionate was added in the feed $5 \mathrm{~g} \cdot \mathrm{L}^{-1}$ for phase 6 (days 232.7-237.7) to test whether it could decrease or improve chain elongation rates. Periods (I-V) with stabilized operation $(\mathrm{pH}, \mathrm{HRT})$ and conversion rates for $\geq 5$ HRT were identified to compare chain elongation performance between phases.

Table 1. Conditions applied during operation.

\begin{tabular}{ccccccc}
\hline Phase & Days & Supply & $\begin{array}{c}\text { Flow Rate } \\
{\left[\mathbf{m L} \cdot \mathbf{m i n}^{-1}\right]}\end{array}$ & $\begin{array}{c}\text { SGV } \\
{\left[\mathbf{m} \cdot \mathbf{h}^{-1} \mathbf{1}\right.}\end{array}$ & $\begin{array}{c}\text { HRT } \\
{[\mathbf{d}]}\end{array}$ & $\begin{array}{c}\text { ULV } \\
{\left[\mathbf{m} \cdot \mathbf{h}^{-1} \mathbf{]}\right.}\end{array}$ \\
\hline 1 & $62.7-85.7$ & Continuous gas & 12 & 0.22 & 2 & 3 \\
2 & $87.7-100.8$ & Continuous gas & 120 & 2.2 & 2 & 3 \\
3 & $104.8-149.9$ & Intermittent gas & 11.3 & 3.6 & 2 & 3 \\
4 & $154-188.8$ & Intermittent gas & 11.3 & 3.6 & 1 & 3 \\
5 & $190.7-231.9$ & No gas & 0 & 0 & 1 & 9 \\
6 & $232.7-237.7$ & Propionate, no gas & 0 & 0 & 1 & 9 \\
\hline
\end{tabular}

\subsection{Calculations}

Chain elongation performance was evaluated based on conversion rates $\left(\mathrm{e}^{-} \mathrm{eq} \cdot \mathrm{L}^{-1} \cdot \mathrm{d}^{-1}\right.$; Equation (1)) and selectivity (Equation (2)).

$$
\text { Conversion rate }=\left(\mathrm{n}_{\mathrm{e}, \mathrm{i}} / \mathrm{V}_{\mathrm{r}}\right) \cdot\left(\mathrm{Q}_{\text {out }} \cdot \mathrm{C}_{\mathrm{out}, \mathrm{i}}-\mathrm{Q}_{\mathrm{in}} \cdot \mathrm{C}_{\mathrm{in}, \mathrm{i}}\right)
$$


where $\mathrm{n}_{\mathrm{e}, i}$ refers to the number of electrons in compound $i$ (liquid and gas metabolites quantified as described in the analytical methods section); $\mathrm{V}_{\mathrm{r}}$ is the reactor working volume (L); $Q_{\text {in }}$ is the influent and $Q_{\text {out }}$ the effluent flow rates $\left(\mathrm{L} \cdot \mathrm{d}^{-1}\right)$; and $\mathrm{C}_{\mathrm{in}, i}$ is the concentration in the influent and $\mathrm{C}_{\mathrm{out}, i}$ the concentration in the effluent of compound $i$ $\left(\mathrm{mmol} \cdot \mathrm{L}^{-1}\right)$. The number of electrons are: Lactate $\left(12 \mathrm{e}^{-} \mathrm{eq} / \mathrm{mol}\right)$, acetate $\left(8 \mathrm{e}^{-} \mathrm{eq} / \mathrm{mol}\right)$, propionate $\left(14 \mathrm{e}^{-} \mathrm{eq} / \mathrm{mol}\right), \mathrm{n}$-butyrate $\left(20 \mathrm{e}^{-} \mathrm{eq} / \mathrm{mol}\right), \mathrm{n}$-valerate $\left(26 \mathrm{e}^{-} \mathrm{eq} / \mathrm{mol}\right), \mathrm{n}-$ caproate $\left(32 \mathrm{e}^{-} \mathrm{eq} / \mathrm{mol}\right)$, n-heptylate $\left(38 \mathrm{e}^{-} \mathrm{eq} / \mathrm{mol}\right)$, n-caprylate $\left(44 \mathrm{e}^{-} \mathrm{eq} / \mathrm{mol}\right)$, hydrogen $\left(2 \mathrm{e}^{-} \mathrm{eq} / \mathrm{mol}\right)$, and methane $\left(8 \mathrm{e}^{-} \mathrm{eq} / \mathrm{mol}\right)$.

Electron selectivity was calculated with respect to liquid and gas metabolites production rates:

$$
\text { Selectivity }=100 \cdot\left[\text { rate }_{\mathrm{i}} /\left(\text { rate }_{\text {liq }}+\sum \text { rate }_{\text {gas }}\right)\right]
$$

where rate ${ }_{i}$ is calculated as in Equation (1) for product $i$; rate $e_{\text {liq }}$ is the production rate of liquid metabolites (propionate, isobutyrate, n-butyrate, isovalerate, n-valerate, isocaproate, $\mathrm{n}$-caproate, $\mathrm{n}$-heptanoate, and n-caprylate); and rate gas is the production rate of gaseous metabolites (hydrogen and methane).

The effect of hydrogen partial pressure $\left(\mathrm{P}_{\mathrm{H} 2}\right)$ on thermodynamics of lactate conversion was evaluated at $\mathrm{pH} 5.5$ and $30^{\circ} \mathrm{C}$. The reactions considered are lactate oxidation to acetate (Equation (3)), lactate conversion to n-butyrate (Equation (4)), n-caproate (Equation (5)), and propionate and acetate (Equation (6)), as well as acetate formation through homoacetogenesis from hydrogen and carbon dioxide (Equation (7)) and from lactate (Equation (8)).

$$
\begin{gathered}
\text { lactate }^{-}+\mathrm{H}_{2} \mathrm{O} \rightarrow \text { acetate }^{-}+2 \mathrm{H}_{2}+\mathrm{CO}_{2} \\
2 \text { lactate }^{-}+\mathrm{H}^{+} \rightarrow \text { n-butyrate } \\
\end{gathered}
$$

The standard Gibbs free energy change of reactions was calculated using Gibbs free energy of formation values from Kleerebezem and van Loosdrecht (2015) [26] and adjusted for temperature, $\mathrm{pH}, \mathrm{P}_{\mathrm{H} 2}$, and reactants concentration according to Equation (9).

$$
\Delta G^{\prime}=\Delta G^{\circ}+R \cdot T \cdot \ln Q
$$

\subsection{DNA Extraction and Sequencing Analysis}

DNA samples were taken from the middle height sampling port of the reactor, centrifuged at $15,000 \mathrm{rpm}$ for $10 \mathrm{~min}$, and stored at $-20^{\circ} \mathrm{C}$ for DNA extraction and sequencing. DNA was extracted from the biomass pellets (PowerSoil DNA isolation kit) for amplification of the V3-V4 region of 16S rRNA following the Illumina library generation and sequencing method described by Takahashi et al. (2014) [27]. The primer set used (full-length IUPAC nomenclature; forward: 5' TCGTCGGCAGCGTCAGATGTGTATAAGAGACAGCCTACGGGNGGCWGCAG; reverse: 5' GTCTCGTGGGCTCGGAGATGTGTATAAGAGACAGGACTACHVGGGTATCTAATCC) allowed for simultaneous amplification of bacterial and archaeal 16S rDNA [28]. DNA sequences were processed as described previously [4]. In short, the DADA2 pipeline (v. 1.16) [29] was used and the identified amplicon sequence variants (ASV) were submitted to the SILVA database [30] for taxonomic identification (SILVA 138 SSU Ref NR 99). Forward and reverse reads were trimmed at cycles 240 and 220, respectively, based on the quality profiles obtained. Sequences were deposited in the European Nucleotide Archive (ENA) database (https: / /www.ebi.ac.uk/ena, accessed on 19 March 2021) under the accession number PRJEB43372. Species assignment is based on exact sequence matching. Selected sequences with a non-exact match were submitted to NCBI BLAST query (megablast $16 \mathrm{~S}$ rRNA bacterial and archaeal gene se- 
quences) and the percentage of identity was reported. ASVs with $\geq 0.01 \%$ of total counts were used for further analyses. Statistical analyses were done using R Studio (v. 1.3.959). Shannon diversity index boxplots were obtained using the InteractiveDisplay package (v. 1.26.0) [31]. Normalized counts using the cumulative sum scaling (CSS) method [32] were used for distance-based redundancy analysis (dbRDA) and canonical correspondence analysis (CCA). dbRDA was done using Bray-Curtis dissimilarity with the capscale function and CCA with the CCA function, both from the vegan package (v. 2.5.7) [33]. Visualization was done using the ggord (v. 1.1.5) [34] and ggplot2 (v. 3.3.3) [35] packages.

\subsection{Analytical Methods}

Aqueous samples were centrifuged at $10,000 \mathrm{rpm}$ for $10 \mathrm{~min}$ and stored at $-4{ }^{\circ} \mathrm{C}$ before analyses. Gas chromatography was used for carboxylate (C2-C8) and alcohol (C1-C6) quantification with an injection volume of $1 \mu \mathrm{L}$ [21]. Lactate, succinate, and formate were measured by injecting $20 \mu \mathrm{L}$ of the sample into an HPLC equipped with a refractive index detector [4]. Lactate enantiomers (D-lactate and L-lactate) were separated and quantified with a chiral column Astec CLC-L $(15 \mathrm{~cm} \times 4.6 \mathrm{~mm}, 5 \mu \mathrm{m})$ (Supelco) using isocratic HPLC (Thermo Scientific Dionex UltiMate 3000 RS, Thermo Fischer) with UV-detection at $254 \mathrm{~nm}$ (Dionex UltiMate VWD-3400). The mobile phase was $5 \mathrm{mM}$ cupric sulfate at $1 \mathrm{~mL} / \mathrm{min}$ and injection volume of $30 \mu \mathrm{L}$. The temperature in the column oven was $25{ }^{\circ} \mathrm{C}$. Chromatography data were analyzed with Chromeleon software (v6.8).

Nitrogen, oxygen, methane, and carbon dioxide were measured using GC (Shimadzu GC-2010, Japan) equipped with thermal conductivity detection (TCD) and a parallel column setup (gas split 1:1) of Agilent PoraBOND Q $(50 \mathrm{~m} \times 0.53 \mathrm{~mm} \times 10 \mu \mathrm{m})$ and Molsieve 5A $(25 \mathrm{~m} \times 0.53 \mathrm{~mm} \times 50 \mu \mathrm{m})$. Carrier gas was helium at $22.5 \mathrm{~mL} \cdot \mathrm{min}^{-1}$. The oven temperature was $80{ }^{\circ} \mathrm{C}$ and TCD $150{ }^{\circ} \mathrm{C}$. Hydrogen was measured with an HP 5890 gas chromatograph by injecting $100 \mu \mathrm{L}$ of the gas sample on a Molsieve 5A column $(30 \mathrm{~m} \times 0.53 \mathrm{~mm} \times 25 \mu \mathrm{m})$ with thermal conductivity detection (TCD). The oven temperature was $40^{\circ} \mathrm{C}$ and $\mu$-TCD $150{ }^{\circ} \mathrm{C}$. The carrier gas was argon with a flow rate of $20 \mathrm{~mL} \cdot \mathrm{min}^{-1}$. Solid samples were taken from the middle height of the column and after a gas pulse during phases of intermittent gas addition for mixed liquor suspended solids quantification. Total (TSS) and volatile (VSS) suspended solids were measured following standard methods [15]. Liquid samples were centrifuged at 10,000 rpm for $20 \mathrm{~min}$. The supernatant was filtered, and the pellet was placed onto the filter paper using demi-water. Samples were dried to at $105^{\circ} \mathrm{C}$ for at least $12 \mathrm{~h}$ before TSS weighing and then placed in an oven at $550{ }^{\circ} \mathrm{C}$ for $2-3 \mathrm{~h}$ to quantify VSS. Raw chemical experimental data are available in the 4TU.ResearchData repository (https: / / doi.org/10.4121/14208530.v1, accessed on 19 March 2021).

\section{Results}

\subsection{Lactate Conversion Performance and Biomass Growth}

After an initial time period of fluctuating $\mathrm{pH}$ and HRT values, lactate conversion rates stabilized and n-caproate became dominant (Figure $1 \mathrm{~A}, \mathrm{~B}$ ). Then, continuous gas supply was started in phase 1 at $12 \mathrm{~mL} \cdot \mathrm{min}^{-1}\left(\mathrm{SGV}=0.22 \mathrm{~m} \cdot \mathrm{h}^{-1}\right)$. By the end of phase 1 (period I), about $40 \%$ of the fed lactate was converted $\left(1.2 \pm 0.04 \mathrm{e}^{-} \mathrm{eq} \cdot \mathrm{L}^{-1} \cdot \mathrm{d}^{-1}\right.$; $8.9 \pm 0.3 \mathrm{~g} \cdot \mathrm{L}^{-1} \cdot \mathrm{d}^{-1}$ ) to mainly n-caproate (Figure S3). n-caproate was produced at concentrations of $5.4 \pm 0.2 \mathrm{~g} \cdot \mathrm{L}^{-1}$ with productivities and selectivities of $0.7 \pm 0.4 \mathrm{e}^{-} \mathrm{eq} \cdot \mathrm{L}^{-1} \cdot \mathrm{d}^{-1}$ $\left(2.6 \pm 0.1 \mathrm{~g} \cdot \mathrm{L}^{-1} \cdot \mathrm{d}^{-1}\right)$ and $60 \pm 6 \%$, respectively (Figure 2$)$. n-heptylate and n-caprylate were produced at selectivities of $5 \pm 2 \%$ and $2 \pm 1 \%$, respectively. Mixed liquor biomass concentrations remained comparable during operation with and without gas addition (Figure 1C) and a thin biofilm was formed on the reactor walls with gas supply (Figure S2). To increase the gas mixing, the gas supply was increased 10 -fold $\left(120 \mathrm{~mL} \cdot \mathrm{min}^{-1} ; \mathrm{SGV}=2.2 \mathrm{~m} \cdot \mathrm{h}^{-1}\right)$ in phase 2, which resulted in degradation of chain elongation activity with n-butyrate and propionate increasing at the expense of n-caproate formation. Some of the biofilm detached due to the increased gas addition settling at the bottom of the column but not to 
a measurable sludge bed height (Figure S2). The gas supply was reduced back to similar volumetric flows to phase 1 but added intermittently thereafter (phases 3 and 4) to keep high gas mixing. Intermittent gas supply was done at $11.3 \mathrm{~mL} \cdot \mathrm{min}^{-1}$ with a resulting $\mathrm{SGV}$ of $3.6 \mathrm{~m} \cdot \mathrm{h}^{-1}$. Initially, the gas bursts pressurized the recirculation line, causing a wash out of biomass. Therefore, the reactor had to be re-inoculated (190 mL effluent) and put in batch on days 104.8-109. Continuous reactor operation with intermittent gas supply was resumed after the batch phase and once the recirculation line was reinforced. During period II, lactate was converted at $45 \%$ higher rates of $1.71 \pm 0.41 \mathrm{e}^{-} \mathrm{eq} \cdot \mathrm{L}^{-1} \cdot \mathrm{d}^{-1}$ $\left(12.9 \pm 1.3 \mathrm{~g} \cdot \mathrm{L}^{-1} \cdot \mathrm{d}^{-1}\right)$ compared to period I towards propionate and n-butyrate, which showed selectivities of $25 \pm 2 \%$ and $61 \pm 2 \%$, respectively. Decreasing the HRT to 1 day in phase 4 resulted in a $\sim 50 \%$ increase in lactate conversion rate to $2.5 \pm 0.41 \mathrm{e}^{-} \mathrm{eq} \cdot \mathrm{L}^{-1} \cdot \mathrm{d}^{-1}$ $\left(18.9 \pm 3.1 \mathrm{~g} \cdot \mathrm{L}^{-1} \cdot \mathrm{d}^{-1}\right)$ with $\mathrm{n}$-butyrate and propionate production rates being 1.5 -times and 2-times higher in period III compared to period II. Traces of n-valerate and n-caproate were observed in phases 3 and 4, but n-heptylate and n-caprylate were not produced. Similar mixed liquor biomass concentrations were observed during continuous (phases 1 and 2) and intermittent (phases 3 and 4) gas supply with no noticeable changes in biofilm growth. During intermittent gas supply, detached biofilm particles were being re-suspended with every gas pulse and took a more irregular shape (Figure S2), but they did not grow into a measurable sludge bed. Due to the change in lactate metabolism from MCC to SCC production, the gas supply was stopped in phase 5 to recover chain elongation activity. Propionate and n-butyrate continued to be produced despite gas supply being stopped, but chain elongation activity was recovered after increasing the liquid recirculation rate on day 195.7 (Figure 1A). Once chain elongation was recovered, lactate consumption decreased to comparable rates as in period I and similar product selectivities. The highest $\mathrm{n}$-caprylate production was observed in this period at $0.04 \pm 0.01 \mathrm{e}^{-} \mathrm{eq} \cdot \mathrm{L}^{-1} \cdot \mathrm{d}^{-1}\left(0.13 \pm 0.03 \mathrm{~g} \cdot \mathrm{L}^{-1} \cdot \mathrm{d}^{-1}\right)$ and selectivity of $2.3 \pm 0.4 \%$ (Figure 2 ).

Propionate was added in the feed during phase 6 to test whether propionate was inhibiting chain elongation in phases 3-4 or it could be used as an electron acceptor and instead improve chain elongation rates. Propionate addition at $5 \mathrm{~g} \cdot \mathrm{L}^{-1}$ (similar to phases 3 and 4) improved chain elongation rates with lactate conversion, reaching a maximum of $2.26 \pm 0.15 \mathrm{e}^{-} \mathrm{eq} \cdot \mathrm{L}^{-1} \cdot \mathrm{d}^{-1}\left(17 \pm 1.1 \mathrm{~g} \cdot \mathrm{L}^{-1} \cdot \mathrm{d}^{-1}\right) \cdot \mathrm{n}$-caproate and $\mathrm{n}$-heptylate production rates increased by $\sim 20$ and $\sim 90 \%$ reaching values of $1.22 \pm 0.18 \mathrm{e}^{-} \mathrm{eq} \cdot \mathrm{L}^{-1} \cdot \mathrm{d}^{-1}$ $\left(4.4 \pm 0.7 \mathrm{~g} \cdot \mathrm{L}^{-1} \cdot \mathrm{d}^{-1}\right)$ and $0.23 \pm 0.10 \mathrm{e}^{-} \mathrm{eq} \cdot \mathrm{L}^{-1} \cdot \mathrm{d}^{-1}\left(0.9 \pm 0.3 \mathrm{~g} \cdot \mathrm{L}^{-1} \cdot \mathrm{d}^{-1}\right)$. However, lower mixed liquor biomass concentrations were measured with the addition of propionate compared to the previous phase (Figure 1C). Despite the faster lactate conversion, increased selectivities were obtained for SCC, i.e., n-butyrate and n-valerate instead of MCC. A longer operation time could lead to microbiome adaptation and improved more stable lactate and propionate elongation to odd-chained MCC. This was not possible here due to a $\mathrm{pH}$ drop to 4.7-4.8 due to technical problems with $\mathrm{pH}$ control. At this low $\mathrm{pH}$ conditions, lactate and propionate conversion continued for $<4$ HRT with halved conversion rates and similar product selectivities (data not shown).

Overall, lactate conversion rates were higher when the microbiome produced SCC compared to MCC production at both long (phase 1 vs. phase 3 ) and short (phase 4 vs. phase 5) HRT conditions (Figure 3A,B). Oxidation-reduction potential (ORP) remained stable between -378 and $-401 \mathrm{mV}$ in chain elongation conditions (periods I, IV, and V) and between -412 and $-430 \mathrm{mV}$ in SCC-producing conditions (periods II and III) (Figure 1C). Residual lactate concentrations ranged between $6-17 \mathrm{~g} \cdot \mathrm{L}^{-1}$ during SCC production and between 15-25 g. $\mathrm{L}^{-1}$ during MCC production. The proportions of L-lactate enantiomer over D-lactate (enantiomeric excess $=100 *$ [L-lactate - D-lactate]/[L-lactate + D-lactate $])$ showed a $\sim 10 \%$ enantiomeric excess during SCC production in phase 4 and approached racemic equilibrium ( 1\% L-lactate excess) during chain elongation in phase 5 (Figure S3). Addition of propionate (phase 6) allowed lactate to be converted to longer carboxylates at rates similar to SCC-producing conditions (phase 4) (Figure 3A,B) with doubled apparent specific lactate consumption rates due to lower mixed liquor biomass concentrations 
(Figure 3C,D). Methane production was observed at low proportions $\left(\sim 0.01 \mathrm{e}^{-} \mathrm{eq} \cdot \mathrm{L}^{-1} \cdot \mathrm{d}^{-1}\right.$; $\leq 1 \%$ selectivities) in phases 1,2 , and 5 , and at $\sim 0.05 \mathrm{e}^{-}$eq. $\cdot \mathrm{L}^{-1} \cdot \mathrm{d}^{-1}(<2 \%$ selectivity) in phase 6.
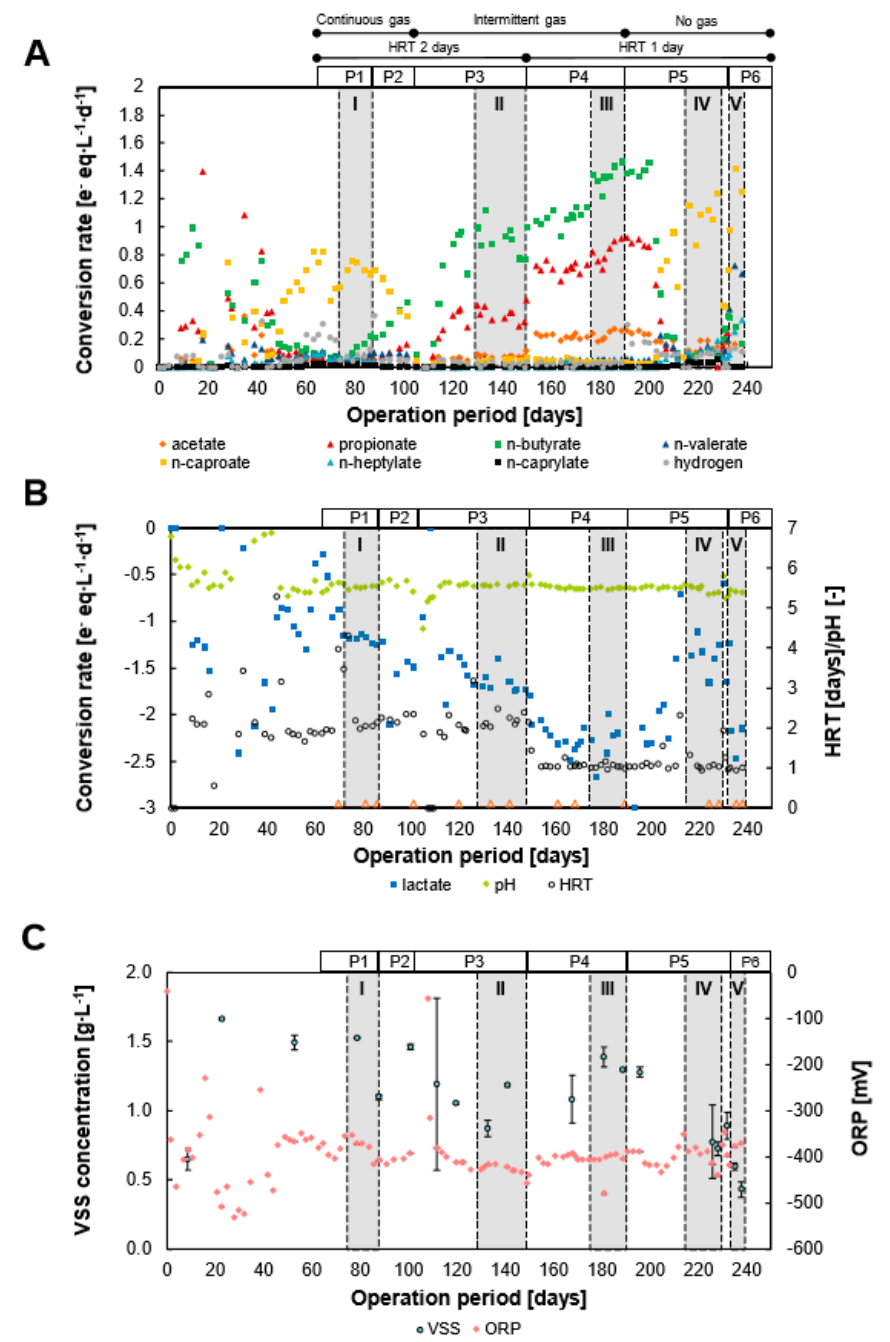

Figure 1. Reactor performance over operation time. (A) Metabolite production rates; (B) hydraulic retention time (HRT), $\mathrm{pH}$, and lactate conversion rates; and (C) volatile suspended solids (VSS) concentrations and oxidation-reduction potential (ORP). Shaded areas indicate periods I-V. Orange triangles indicate DNA sampling days (B).

A

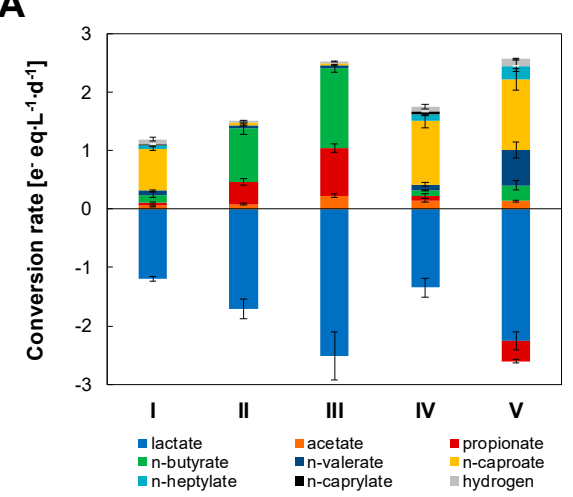

B

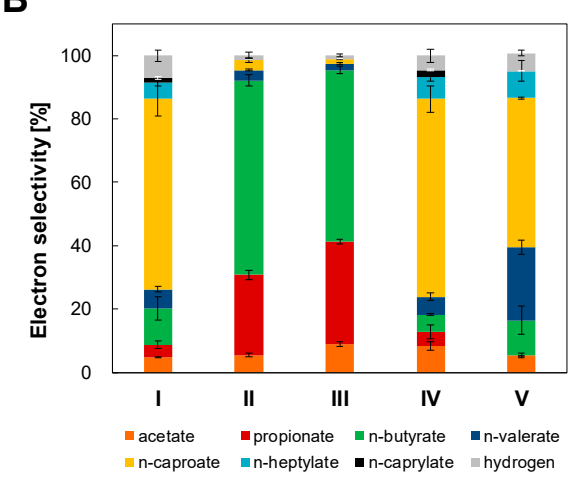

Figure 2. (A) Lactate and metabolites conversion rates and (B) product selectivity during the different stabilized operation periods. 
A

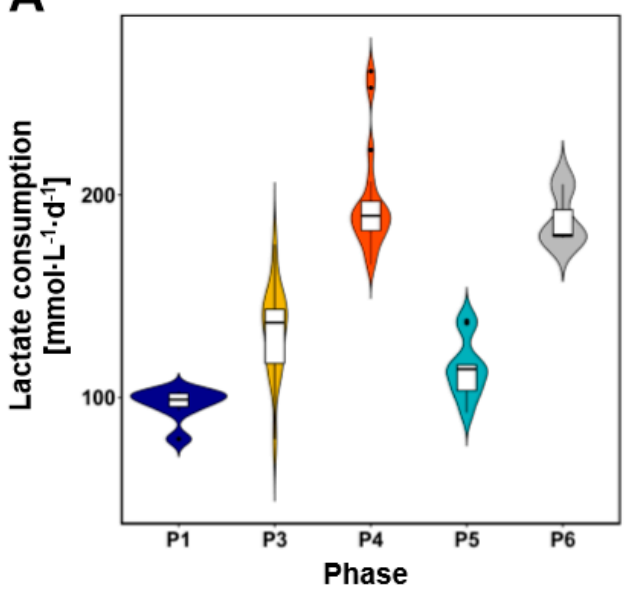

C

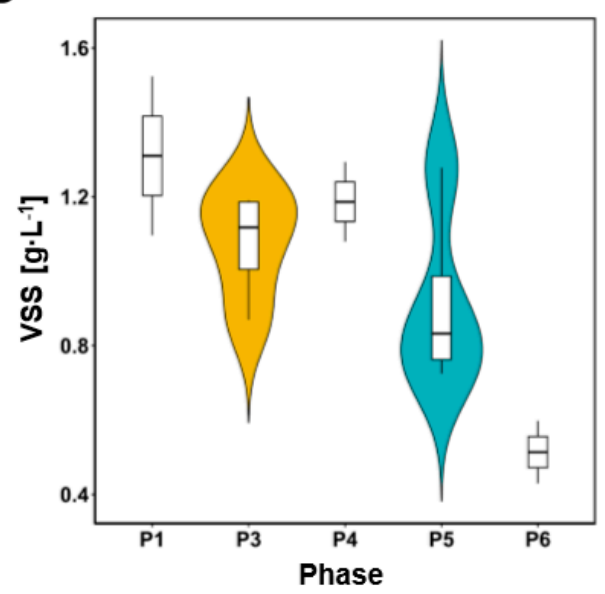

B

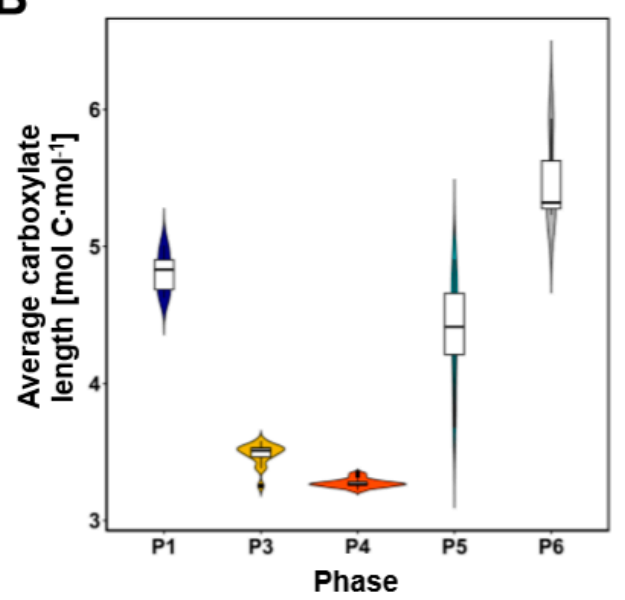

D

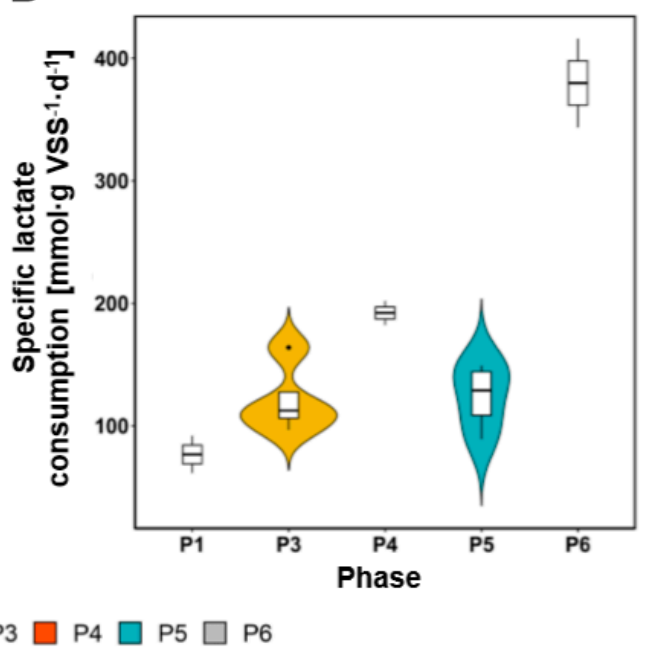

Figure 3. Violin plots showing lactate conversion and biomass concentrations for each operational phase. (A) Lactate consumption rate; (B) average carboxylate length produced; (C) mixed liquor biomass concentration; and (D) specific lactate conversion based on mixed liquor biomass concentrations. Violin shapes show the data kernel probability density with boxplots embedded. Boxplots show the interquartile range (IQR) in boxes divided by median values (horizontal lines) with whiskers depicting $\pm 1.5 \mathrm{IQR}$ and outliers as points. Plots include data from stable HRT and $\mathrm{pH}$ operational days. Phase 2 was excluded and data from days 209.8-231.9 (when chain elongation was recovered) were used for phase 5.

\subsection{Caproiciproducens Outcompeted by Clostridium at High Superficial Gas Velocities}

The reactor microbiomes developed into less diverse microbial communities compared to the initial inoculum (Figure S4) with chain-elongating microbiomes showing higher diversity than SCC-producing microbiomes from phases 3 and 4 (Figure $4 \mathrm{~A}$ ). Both $\mathrm{N}_{2}$ gas flow rate $\left(\mathrm{N}_{2}\right)$ and SGV affected the microbiome composition $(p<0.0005)$ and SCCproducing microbiomes clustered apart from chain-elongating communities (Figure 4B). MCC-producing microbiomes showed similar compositions in phases 5 and 6 but relatively distant from microbiomes from phase 1 . This difference was related to the different HRT and gas flow applied as these two variables were linked to the variation captured by CAP2 (Figure 4B). High SGV applied in phases $2-4$ resulted in decreased relative abundance for the genera Caproiciproducens and Tuzzerella while Clostridium sensu stricto 12 became dominant (Figure 4C). MCC production was linked to increased relative abundance of ASVs belonging to the genera Caproiciproducens, Tuzzerella, Oscillibacter, Haloimpatiens and Clostridium sensu stricto 15 (Figure 4D). Caproiciproducens spp. ASV1, ASV7, and ASV11, Oscillibacter sp. ASV6, and Tuzzerella sp. ASV3 were among the most abundant ASVs in chain-elongating microbiomes from phases 1,5, and 6 (Figure 5) and were strongly related 
to n-caproate production (except ASV7) (Figure 4D). Haloimpatiens sp. ASV5 (99.7\% similar to Haloimpatiens lingqiaonensis) was linked to n-heptylate production. Clostridium cochlearum sp. ASV8 was also related to MCC-producing microbiomes. Microbiomes producing propionate and n-butyrate were related to high SGV and were composed by up to $74 \%$ of Clostridium tyrobutyricum spp. ASV2 and ASV4, except on day 140.8, where Anaerotignum sp. ASV18 was also abundant (Figure 5). C. tyrobutyricum spp. ASV2 and ASV4 were 99.7 and $99.4 \%$ similar to C. tyrobutyricum strain ATCC 25755, respectively.
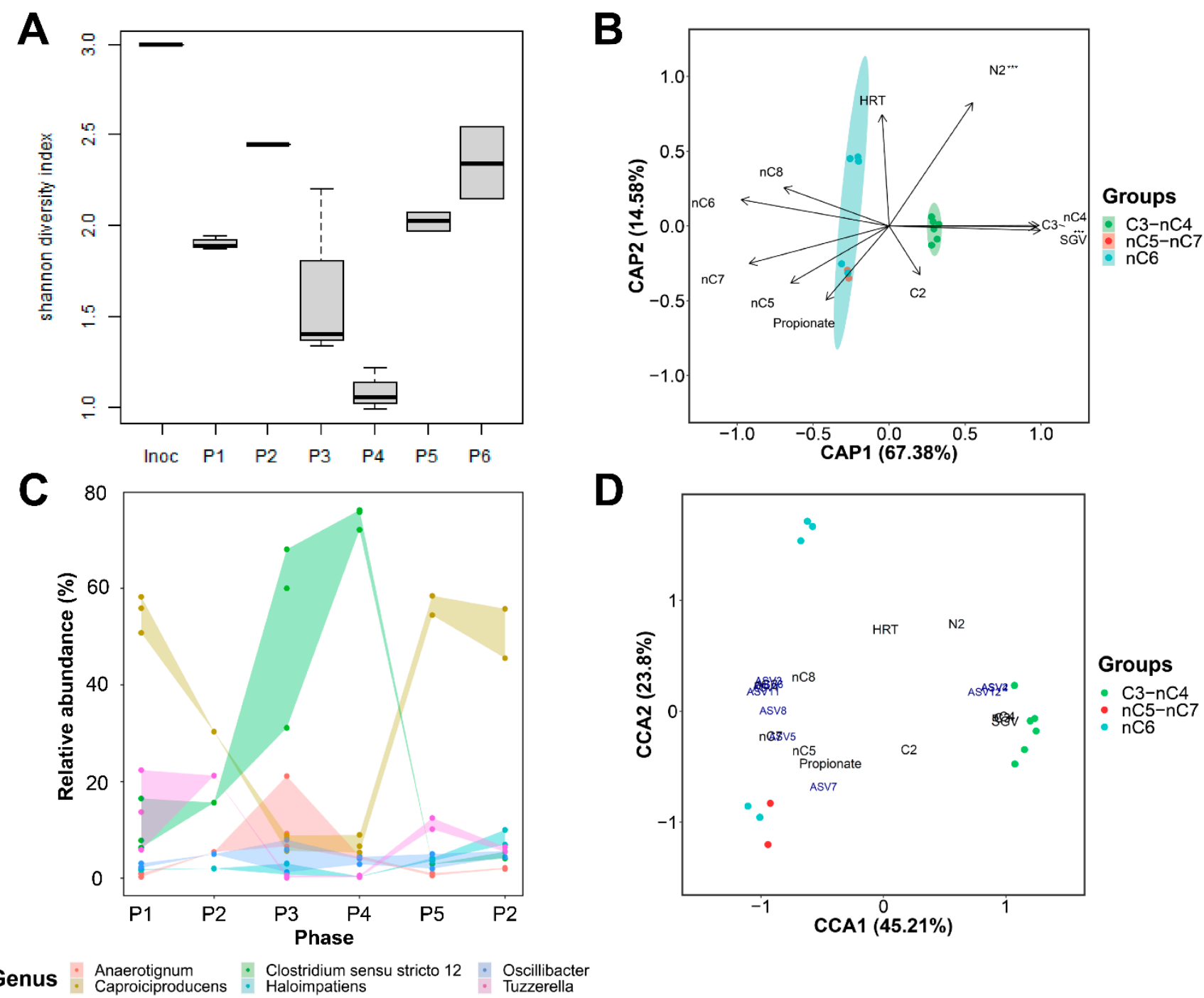

Figure 4. Reactor microbiome dynamics through the operational phases related to environmental conditions. (A) Shannon diversity index. Boxplots show the interquartile range (IQR) in boxes divided by median values (horizontal lines) with whiskers depicting \pm 1.5 IQR. (B) Distance-based redundancy analysis (dbRDA) using Bray-Curtis dissimilarity index and ASV relative abundance as response variables, and environmental parameters as explanatory variables (constraints). Environmental parameters considered were: Gas flow rate $\left(\mathrm{N}_{2}\right)$, SGV, HRT, propionate addition, and metabolite electron selectivities on the DNA sampling days (acetate [C2], propionate [C3], nC4, nC5, nC6, nC7, and nC8). Concentration ellipses depict confidence intervals with $\alpha=0.05$. Significance code: ${ }^{\prime * * * \prime}$ associated with a variable at $p<0.0005$. (C) Relative abundance of dominant genera for each operational phase. Shaded area covers the minimum and maximum relative abundance values. (D) Canonical correspondence analysis (CCA) using Hellinger transformation and same constraints as in dbRDA. CCA triplot shows top 10 ASVs best described by the model scaled proportionally to eigenvalues. Analyses were done using $16 \mathrm{~S}$ rRNA gene sequencing data of ASVs with $>0.01 \%$ of total counts. Counts were CSS-normalized for dbRDA and CCA analyses (C,D). 

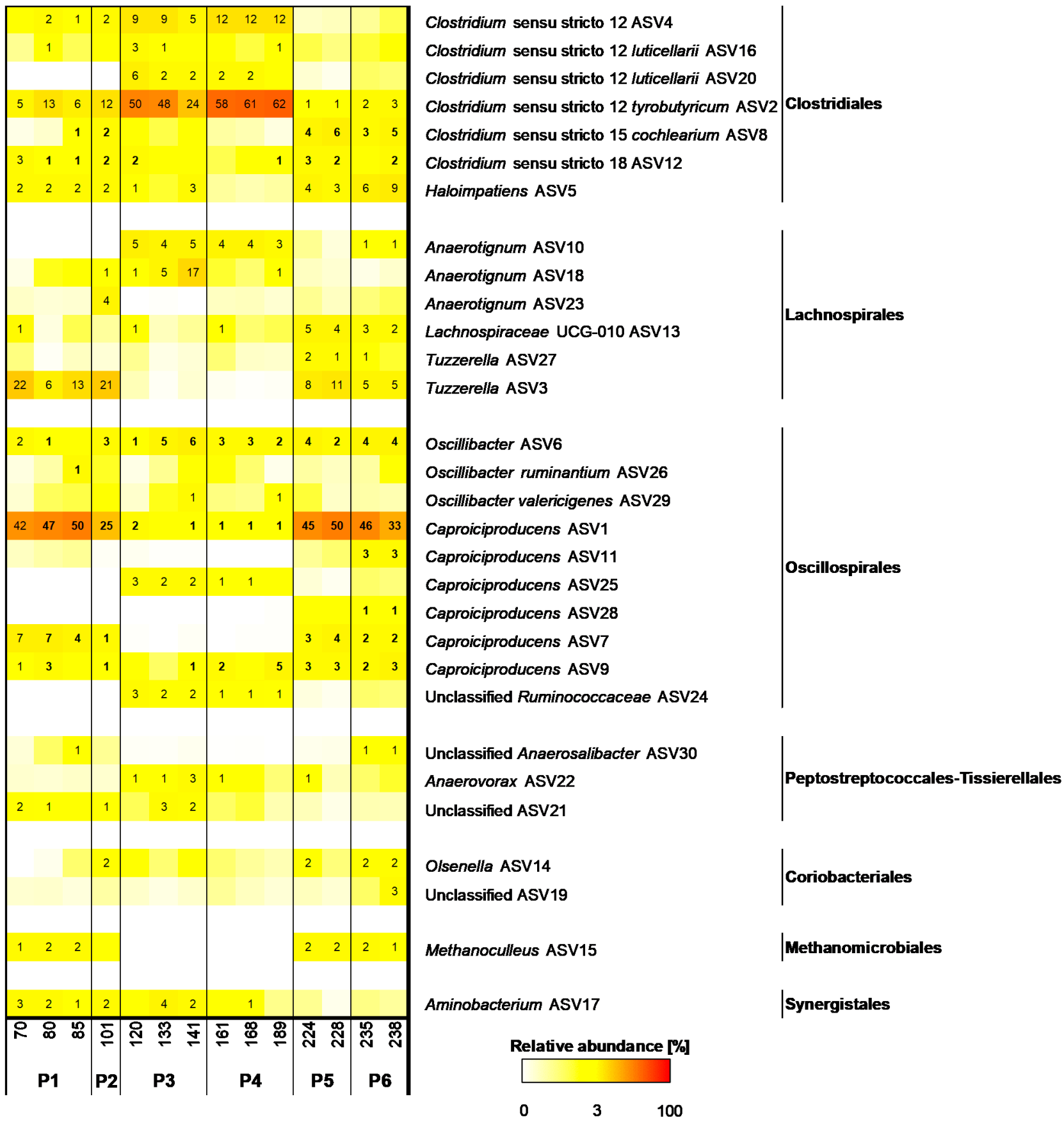

Figure 5. Reactor microbiomes composition at ASV level. Top 30 ASVs are shown and relative abundance values $\geq 1 \%$ are displayed. Sampling days and corresponding operational phases are shown below the heatmap. Taxonomy was assigned based on SILVA 138 SSU Ref NR 99 database.

\section{Discussion}

4.1. Lactate Was Efficiently Converted into MCC at Low Gas Velocities with Conversion Rates Improved after Electron Acceptor Supplementation

In the present study, it was shown that $\mathrm{N}_{2}$ supply can be used for mixing chain elongation reactors with sustained MCC production at SGV $\leq 0.22 \mathrm{~m} \cdot \mathrm{h}^{-1}$. Chain elongation was obtained when $\mathrm{N}_{2}$ was either continuously supplied at $12 \mathrm{~mL} \cdot \mathrm{min}^{-1}$ with an equivalent SGV of $0.22 \mathrm{~m} \cdot \mathrm{h}^{-1}$ (phase 1) or when not supplied at all (phase 5). In both conditions, n-caproate electron selectivity was $\sim 61 \%$ but n-caproate yields from consumed lactate were higher in phase 5 (period IV: $0.31 \pm 0.04 \mathrm{~mol} \mathrm{nC6} \cdot \mathrm{mol}$ lactate $^{-1}$ ) compared 
to phase 1 (period I: $0.23 \pm 0.02 \mathrm{~mol} \mathrm{nC} 6 \cdot \mathrm{mol} \mathrm{lactate}^{-1}$ ), indicating a more efficient lactate conversion in phase 5. Caproiciproducens-related species dominated the suspended microbiome composition in both conditions. The obtained n-caproate yields are similar to yields reported for Ruminococcaceae bacterium CPB6-enriched microbiomes $(0.3 \mathrm{~mol}$ nC6. $\left.\mathrm{mol} \mathrm{lactate}^{-1}\right)$ [7] and pure cultures $\left(0.23 \mathrm{~mol} \mathrm{nC6} \cdot \mathrm{mol} \mathrm{lactate}^{-1}\right)$ [36]. MCC production rates reached $1.25 \pm 0.15 \mathrm{e}^{-} \mathrm{eq} \cdot \mathrm{L}^{-1} \cdot \mathrm{d}^{-1}\left(10 \mathrm{~g} \mathrm{COD} \cdot \mathrm{L}^{-1} \cdot \mathrm{d}^{-1}\right)$ with electron selectivities of $72 \pm 5 \%$ when HRT was kept at 1 day and gas was not supplied (phase 5) with MCC composed of $87 \%$ n-caproate $\left(8.7 \mathrm{~g}\right.$ COD $\left.\cdot \mathrm{L}^{-1} \cdot \mathrm{d}^{-1}\right), 9.5 \%$ n-heptylate $\left(0.97 \mathrm{~g} \mathrm{COD} \cdot \mathrm{L}^{-1} \cdot \mathrm{d}^{-1}\right)$, and $3 \% \mathrm{n}$-caprylate $\left(0.32 \mathrm{~g} \mathrm{COD} \cdot \mathrm{L}^{-1} \cdot \mathrm{d}^{-1}\right)$. In the present study, relatively higher n-caproate production rates (1.3- to 3.8-times) and selectivities (1.5- to 1.8-times) compared to previous reports were obtained. Kucek et al. (2016) [8] obtained a maximum n-caproate productivity of $6.9 \mathrm{~g} \mathrm{COD} \cdot \mathrm{L}^{-1} \cdot \mathrm{d}^{-1}$ in an upflow anaerobic filter fed with L-lactate and n-butyrate using in-line extraction. In a lactate-fed CSTR, Candry et al. (2020) [6] obtained maximum n-caproate concentrations of $36 \mathrm{mM}$ at $\mathrm{pH} 6$ and HRT of 4 days equivalent to a maximum n-caproate production rate of $2.3 \mathrm{~g} \mathrm{COD} \cdot \mathrm{L}^{-1} \cdot \mathrm{d}^{-1}$. $\mathrm{n}$-caproate selectivities reported in the mentioned studies reached maximum values of 34 and $41 \%$, respectively.

Despite the consumed lactate was efficiently converted into MCC during phases 1 and 5,46 and $70 \%$ of the fed lactate at HRT of 2 and 1 days, respectively, was not converted. Added propionate (phase 6) increased lactate consumption rates by 1.7-times $\left(2.26 \pm 0.15 \mathrm{e}^{-} \mathrm{eq} \cdot \mathrm{L}^{-1} \cdot \mathrm{d}^{-1} ; 18 \mathrm{~g} \mathrm{COD} \cdot \mathrm{L}^{-1} \cdot \mathrm{d}^{-1}\right)$ by acting as an electron acceptor and reducing the unconverted lactate fraction to $55 \%$ at 1 day HRT. As a result, n-caproate and $\mathrm{n}$-heptylate production reached maximum values of $1.21 \pm 0.18 \mathrm{e}^{-} \mathrm{eq} \cdot \mathrm{L}^{-1} \cdot \mathrm{d}^{-1}$ $\left(9.7 \mathrm{~g} \mathrm{COD} \cdot \mathrm{L}^{-1} \cdot \mathrm{d}^{-1}\right)$ and $0.23 \pm 0.10 \mathrm{e}^{-} \mathrm{eq} \cdot \mathrm{L}^{-1} \cdot \mathrm{d}^{-1}\left(1.8 \mathrm{~g} \mathrm{COD} \cdot \mathrm{L}^{-1} \cdot \mathrm{d}^{-1}\right)$, respectively, indicating that lactate-based chain elongation rates can be significantly improved with the addition of an electron acceptor. The use of an electron acceptor may allow chainelongating bacteria to harvest more ATP, thereby increasing chain elongation rates $[24,37]$. It is assumed that acetate and propionate compete for the same enzyme system with a preference for acetate in the RBO pathway [12]. In the present study, acetate concentrations (7.1-18.3 $\mathrm{mM}$ ) were 2-3 times higher than propionate $(3.5-5.6 \mathrm{mM})$ during chain elongation without electron acceptor supply (periods I and IV) which may help explain the high evenchain (nC4, nC6 plus nC8, 73\% selectivity) over odd-chain (nC5 and nC7, 12\% selectivity) products. However, residual propionate concentrations $(42 \mathrm{mM})$ were higher than acetate $(24 \mathrm{mM})$ when adding propionate, which may have compensated for a lower enzyme affinity, increasing odd-chain product selectivity to $32 \%$ (58\% for even-chain products). About $40 \%$ of the added propionate was consumed $\left(\sim 25 \mathrm{mmol} \cdot \mathrm{L}^{-1} \cdot \mathrm{d}^{-1}\right)$ with a corresponding odd-chain carboxylate production ( $\mathrm{nC} 5$ and $\mathrm{nC} 7$ ) of $\sim 29 \mathrm{mmol} \cdot \mathrm{L}^{-1} \cdot \mathrm{d}^{-1}$. These values indicate stoichiometric conversion of consumed propionate to odd chains. Alcohols (C1-C6) and branched-chain carboxylates were not detected in any operational phase. The extra $4 \mathrm{mmol} \cdot \mathrm{L}^{-1} \cdot \mathrm{d}^{-1}$ of odd-chain products could originate from in situ-produced propionate. In situ-produced propionate seemed to be reduced by a factor of $\sim 3$ when external propionate was added $\left(5 \mathrm{~g} \cdot \mathrm{L}^{-1} ; 13 \mathrm{mM}\right.$ undissociated propionic acid), considering that odd chains (propionate, $\mathrm{nC} 5$, and $\mathrm{nC} 7$ ) were produced at $\sim 13 \mathrm{mmol} \cdot \mathrm{L}^{-1} \cdot \mathrm{d}^{-1}$ in the previous period (period IV) when only lactate was fed. Although the propionate concentrations added did not inhibit chain elongation, relatively lower mixed liquor biomass concentrations were observed (phase 5 vs. phase 6), resulting in apparent 3-times higher specific lactate consumption rates compared to lactate-elongation with no electron acceptor ( $136 \mathrm{mmol}$ lactate.g VSS ${ }^{-1} \cdot \mathrm{d}^{-1}$ vs. $\sim 380 \mathrm{mmol}$ lactate.g VSS $\left.{ }^{-1} \cdot \mathrm{d}^{-1}\right)$. Suspended biomass growth seemed to dominate in the reactor, although the contribution of biofilms and aggregates present in the reactor to the measured lactate conversion and chain elongation rates was not well characterized. However, biomass aggregation into sludge beds typically observed in high-rate granular reactors was not observed [17]. Chain-elongating microbiomes with propionate supplementation were also dominated by Caproiciproducens-related species. Increased proportions of Haloimpatiens and C. cochlearum species was observed which have no reported role in MCC production. Haloimpatiens species have recently 
been enriched in chain elongation microbiomes fermenting a mixture of lactose, lactate, ethanol, and acetate [38]. MCC selectivities were reduced upon propionate addition due to a marked increase in n-valerate electron selectivity to $23 \pm 2 \%\left(4.8 \mathrm{~g} \mathrm{COD} \cdot \mathrm{L}^{-1} \cdot \mathrm{d}^{-1}\right)$, while n-heptanoate selectivity was $9 \pm 3 \%$. Future studies may focus on improving long-term n-heptylate production from lactate and propionate, as has been done for the ethanol-based chain elongation process for which an n-heptylate production of $10.4 \mathrm{~g} \mathrm{COD} \cdot \mathrm{L}^{-1} \cdot \mathrm{d}^{-1}$ and $23 \%$ selectivity has been achieved [10].

\subsection{High Gas Velocities and Dilution Rates May Favor Fast Lactate Metabolism}

Supply of $\mathrm{N}_{2}$ at high rates had a marked effect on lactate conversion and microbiome composition. The SCC acetate, propionate, and n-butyrate were the main fermentation products when gas was supplied at SGV $>2 \mathrm{~m} \cdot \mathrm{h}^{-1}$. Chain elongation showed a decreasing trend during continuous gas supply at SGV of $2.2 \mathrm{~m} \cdot \mathrm{h}^{-1}$ (phase 2), while SCC were persistently produced during intermittent gas supply at SGV of $3.6 \mathrm{~m} \cdot \mathrm{h}^{-1}$ (phases 3 and 4). Although biomass concentrations were only slightly lower during operation at high SGV (phases 2-4) compared to low SGV (phase 1), the microbiome composition was completely changed to a dominance of Clostridium tyrobutyricum species. The Clostridium tyrobutyricum type strain ATCC 25755 is usually regarded as an efficient n-butyrate producer through the RBO pathway [39]. The type strain ATCC 25755 and several other strains are also capable of producing propionate, isobutyrate, and n-valerate [40], although the propionate production pathway for this species is not described. Likely, the strong change in microbiome composition and metabolites profile was caused by washout of MCCproducing chain-elongating bacteria due to high gas velocities. In high-rate reactors, hydrodynamic shear force created with gas supply is reported to favor biomass aggregation into granules. Hydrodynamic shear force effected with continuous $\mathrm{N}_{2}$ supply at an SGV of $0.24 \mathrm{~m} \cdot \mathrm{h}^{-1}$ increased nucleation rates and granular sludge properties in a UASB anaerobic digester [17]. Applying shear force via aeration at SGV $>4 \mathrm{~m} \cdot \mathrm{h}^{-1}$ led to compact granule formation in sequential aerobic sludge blanket reactors [18]. Despite similar SGV being applied in the present study $\left(0.22-3.6 \mathrm{~m} \cdot \mathrm{h}^{-1}\right)$, measurable granular sludge was not obtained. Instead, chain-elongating bacteria were washed out and SCC-producing microbiomes with a faster lactate metabolism were enriched. This indicates that the first step of chain elongation (acetate to nC4) occurs at higher rates than the second step (nC4 to nC6), with the first step being selected at high gas velocities.

Moreover, increased production of propionate (period IIII: $0.82 \pm 0.07 \mathrm{e}^{-} \mathrm{eq} \cdot \mathrm{L}^{-1} \cdot \mathrm{d}^{-1}$; $\left.6.6 \mathrm{~g} \mathrm{COD} \cdot \mathrm{L}^{-1} \cdot \mathrm{d}^{-1}\right)$, to the detriment of $\mathrm{n}$-butyrate, allowed higher lactate consumption rates at similar biomass concentrations when HRT was reduced to 1 day (phase 3 vs. phase 4). Although $\mathrm{pH}$ conditions below 6 units can effectively limit growth of known propionate-producing bacteria and promote lactate-based chain elongation [6], propionate was produced at high rates in the present study. A previous study also showed propionate production (5.5 g COD $\cdot \mathrm{L}^{-1} \cdot \mathrm{d}^{-1}$ ) over chain elongation at high lactate loading rates $\left(\sim 16 \mathrm{~g} \mathrm{COD} \cdot \mathrm{L}^{-1} \cdot \mathrm{d}^{-1}\right)$, HRT 1.5 days, and $\mathrm{pH} 5.0$ in lactate-fed reactor microbiomes [8]. The production of propionate might allow bacteria to cope with conditions of high lactate loading (up to $37 \mathrm{~g}$ COD $\cdot \mathrm{L}^{-1} \cdot \mathrm{d}^{-1}$ ) and dilution (high SGV and short HRT) rates as applied in phases 3 and 4 . This is supported by observations with pure cultures where lactate conversion to propionate allowed for higher growth rates at $\mathrm{pH} \sim 7\left(0.12-0.33 \mathrm{~h}^{-1}\right)$ [9] and $\mathrm{pH} \geq 5.0\left(0.66 \mathrm{~h}^{-1}\right)$ [41] compared to n-butyrate from lactate and acetate at $\mathrm{pH} 6.2$ $\left(0.05 \mathrm{~h}^{-1}\right)$ [42]. These results open the opportunity of increasing the productivity and broadening the product spectrum of lactate-based chain elongation in, for instance, a two-stage system. Lactate conversion could be steered toward SCC (e.g., propionate or $\mathrm{nC} 4$ ) by supplying $\mathrm{N}_{2}$ to a first reactor which can then be fed as electron acceptors in a second reactor for chain elongation to $\mathrm{MCC}$ (e.g., $\mathrm{nC7}$ or $\mathrm{nC} 8$ ) potentially achieving high lactate conversion rates in both stages. 


\subsection{Shift from MCC to SCC Production Was Unrelated to Hydrogen Partial Pressure}

$\mathrm{N}_{2}$ supply at high levels decreased partial pressures of hydrogen $\left(\mathrm{P}_{\mathrm{H} 2}\right)$ and carbon dioxide $\left(\mathrm{P}_{\mathrm{CO} 2}\right)$ which could affect chain elongation. It is known that $\mathrm{CO}_{2}$ is required for amino acid synthesis and growth in ethanol-elongating bacteria, such as Clostridium kluyveri becoming limiting at concentrations below $3 \mathrm{mM}$ [43]. In the present study, calculated dissolved inorganic carbon $\left(\sim 90 \% \mathrm{H}_{2} \mathrm{CO}_{3}\right.$ at $\mathrm{pH}$ 5.5) increased from $10 \mathrm{mM}$ in phase 1 to $20 \mathrm{mM}$ in phase 2 to then decrease to $3-4 \mathrm{mM}$ in phases 3 and 4 . Thus, although $\mathrm{CO}_{2}$ availability might have limited chain elongation in phases 3 and 4 , this was not the case for phase 2. Additionally, the $\mathrm{CO}_{2}$ requirements of lactate-elongating bacteria remain to be studied. Dissolved inorganic carbon was $17-18 \mathrm{mM}$ during chain elongation without gas supply (phases 5 and 6).

Decreased $\mathrm{P}_{\mathrm{H} 2}$ caused by the $\mathrm{N}_{2}$ supply did not seem to have caused the shift from n-caproate to n-butyrate production either. Observed $\mathrm{P}_{\mathrm{H} 2}$ during chain elongation with continuous gas supply at $12 \mathrm{~mL} \cdot \mathrm{min}^{-1}\left(\mathrm{SGV}=0.22 \mathrm{~m} \cdot \mathrm{h}^{-1}\right)($ period I, $0.10 \pm 0.03 \mathrm{~atm})$ was lower than $\mathrm{P}_{\mathrm{H} 2}$ reached at $120 \mathrm{~mL} \cdot \mathrm{min}^{-1}\left(\mathrm{SGV}=2.2 \mathrm{~m} \cdot \mathrm{h}^{-1}\right)$ (phase $2 \sim 0.23 \mathrm{~atm}$ ) at which chain elongation first declined. The Gibbs free energy change $\left(\Delta \mathrm{G}^{\prime}\right)$ calculated from concentrations measured in period I suggested that $\mathrm{P}_{\mathrm{H} 2}$ had a negligible effect on determining whether n-butyrate or n-caproate is dominant (Figure 6). The efficient conversion of lactate to $\mathrm{n}$-caproate in this period resulted in low n-butyrate concentrations, making n-butyrate formation (Equation (4)) more thermodynamically favorable than ncaproate (Equation (5)). Other parameters such as preferred $\mathrm{pH}[36,42]$, use of SCC as electron acceptors [1], and energetics of chain-elongating bacteria [37] may explain the dominance of n-caproate production over acetate and n-butyrate. Formation of propionate along with acetate (Equation (6)) is independent of $\mathrm{P}_{\mathrm{H} 2}$ and was more thermodynamically favorable than n-butyrate and n-caproate. Thus, $\mathrm{P}_{\mathrm{H} 2}$ thermodynamics does not seem to explain the shift from n-caproate to propionate and n-butyrate production. This indicates that chain-elongating Caproiciproducens species were likely kinetically outcompeted by SCC-producing Clostridium species under high shear and loading stress as discussed before (Section 4.2).

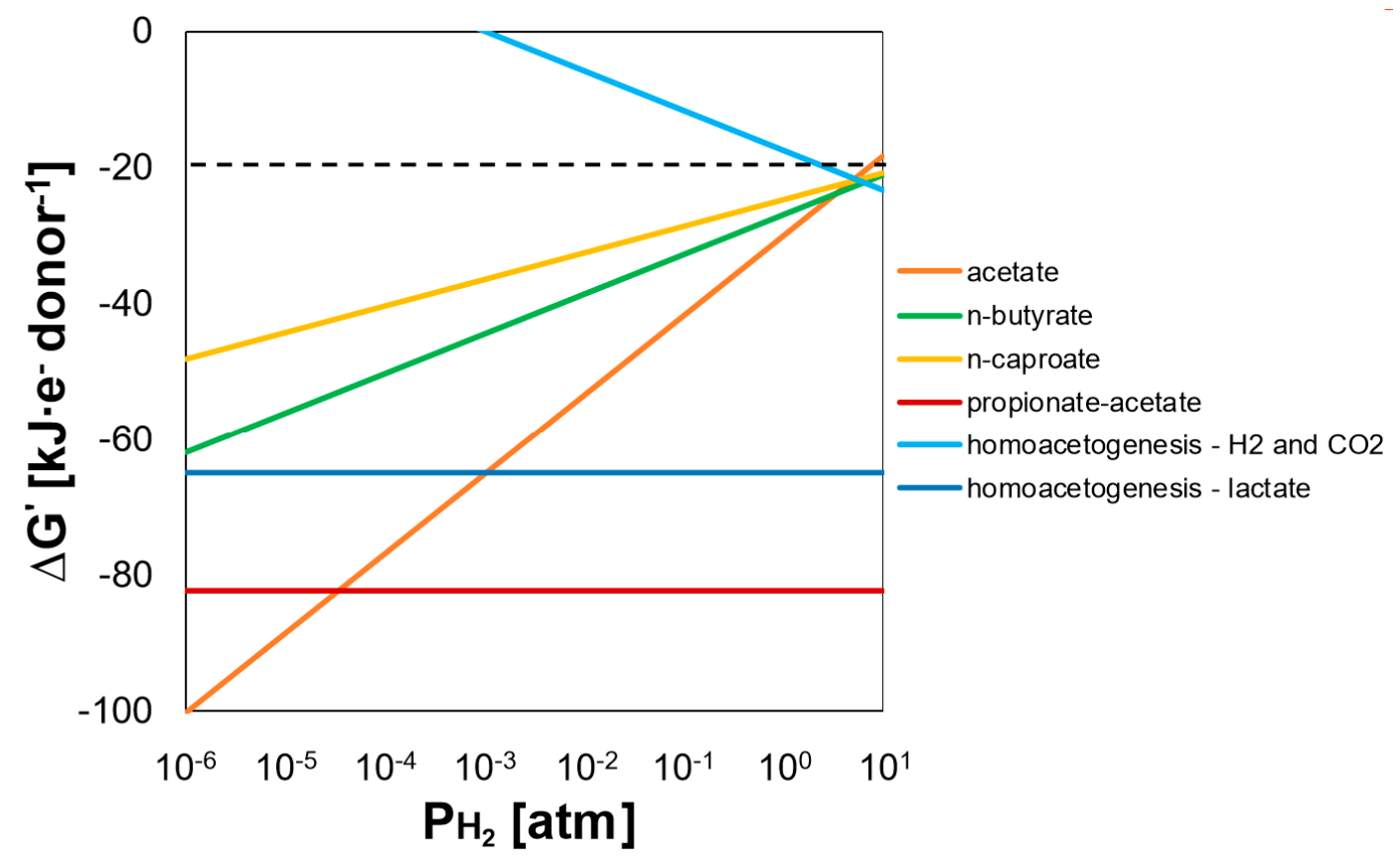

Figure 6. Actual Gibbs free energy change $\left(\Delta G^{\prime}\right)$ of lactate fermentation reactions and homoacetogenesis (Section 2.3) as a function of hydrogen partial pressure $\left(\mathrm{P}_{\mathrm{H} 2}\right)$ with concentrations of period $\mathrm{I}, \mathrm{pH} 5.5$, and $30^{\circ} \mathrm{C}$. A minimum free energy change of $20 \mathrm{~kJ} \cdot \mathrm{e}^{-}$donor $^{-1}$ (dashed line) was assumed to be required for a reaction to be feasible [44]. 
Lactate conversion to MCC has been improved in incubations with external hydrogen addition [14]. This improvement was shown to result from increased homoacetogenesis and acetate and propionate hydrogenation to their respective alcohols to then be used as electron donors/acceptors in chain elongation. Hydrogen supplementation also improved $\mathrm{n}$-caproate formation from food waste fermentation leachate containing mainly lactate [45]. In the present study, no alcohols were detected throughout the operation time. Bacteria capable of performing homoacetogenesis such as Oscillibacter [46] and Clostridium luticellarii [47] were present in chain-elongating microbiomes. However, homoacetogenesis from $\mathrm{H}_{2}$ and $\mathrm{CO}_{2}$ did not seem likely to occur $\left(\Delta \mathrm{G}^{\prime}<20 \mathrm{~kJ} \cdot \mathrm{e}^{-}\right.$donor $\left.^{-1}\right)$ at the $\mathrm{P}_{\mathrm{H} 2}$ observed here ( $0.1 \mathrm{~atm}$ period I; $\sim 0.3 \mathrm{~atm}$ periods IV-V). Alternatively, homoacetogens may produce acetate from lactate independent of $\mathrm{P}_{\mathrm{H} 2}$ and $\mathrm{P}_{\mathrm{CO} 2}$ (Equation (8)) [48] which was a feasible reaction throughout the operation time $\left(-65\right.$ to $-57 \mathrm{~kJ} \cdot \mathrm{e}^{-}$donor $\left.{ }^{-1}\right)$. However, $\mathrm{H}_{2}$ and $\mathrm{CO}_{2}$ yields during chain elongation periods indicate that lactate was primarily converted to n-caproate according to Equation (5). $\mathrm{H}_{2}$ yields were $1.36 \pm 0.37$ and $1.41 \pm 0.26 \mathrm{~mol}$ $\mathrm{H}_{2} \cdot$ mol lactate ${ }^{-1}$ during chain elongation in periods I and $\mathrm{IV}$, respectively. $\mathrm{CO}_{2}$ yields averaged $0.73 \pm 0.25 \mathrm{~mol} \mathrm{CO}_{2} \cdot \mathrm{mol} \mathrm{lactate}{ }^{-1}$ and $1.03 \pm 0.16 \mathrm{~mol} \mathrm{CO} \cdot \mathrm{mol} \mathrm{lactate}^{-1}$ in periods I and IV, respectively. These values are close to or higher than the $\mathrm{H}_{2}$ and $\mathrm{CO}_{2}$ yields expected from chain elongation according to Equation (5) $\left(0.67 \mathrm{~mol} \mathrm{H}_{2} \cdot \mathrm{mol} \mathrm{lactate}^{-1}\right.$; $1 \mathrm{~mol} \mathrm{CO}_{2} \cdot \mathrm{mol} \mathrm{lactate}^{-1}$ ). Thus, homoacetogenesis seemed to have little or no contribution in chain-elongating microbiomes with and without $\mathrm{N}_{2}$ supply.

\section{Conclusions}

The supply of $\mathrm{N}_{2}$ was observed to impact the microbiome composition and, subsequently, lactate conversion processes dependent on the superficial gas velocity (SGV) applied. Production of MCC through lactate-based chain elongation occurred when $\mathrm{N}_{2}$ was supplied at SGV of $0.22 \mathrm{~m} \cdot \mathrm{h}^{-1}$ with similar product selectivities to operation without $\mathrm{N}_{2}$ supply. Chain elongation conditions enriched for organisms from the genera Caproiciproducens, Tuzzerella, Oscillibacter, and Haloimpatiens. Higher SGV $\left(2.2\right.$ and $\left.3.6 \mathrm{~m} \cdot \mathrm{h}^{-1}\right)$ washed out chain-elongating bacteria and enriched SCC-producing microbiomes dominated by Clostridium tyrobutyricum converting lactate into acetate, propionate, and n-butyrate at higher rates. Lactate conversion into MCC occurred at similar rates as in SCC-producing conditions only when added propionate served as electron acceptor. Suspended biomass growth seemed to dominate, and biomass aggregation typically observed in high-rate granular reactors was not observed at the SGV applied here $\left(0.22-3.6 \mathrm{~m} \cdot \mathrm{h}^{-1}\right)$. Based on the results of this study, $\mathrm{N}_{2}$ supplementation at $\mathrm{SGV} \leq 0.22 \mathrm{~m} \cdot \mathrm{h}^{-1}$ is suitable to provide mixing in lactate-based chain elongation bioprocesses, while SGV $>2 \mathrm{~m} \cdot \mathrm{h}^{-1}$ can severely affect microbiome composition and MCC production. $\mathrm{N}_{2}$ supply may be useful to increase conversion rates and broaden the product spectrum of lactate-based chain elongation in two-stage systems.

Supplementary Materials: The following are available online at https://www.mdpi.com/2311 $-5637 / 7 / 1 / 41 /$ s1, Figure S1: Schematic of upflow anaerobic reactor set-up; Figure S2: Biomass appearance (A) before continuous gas supply (day 57.7); (B) during continuous gas supply at 12 $\mathrm{mL} \cdot \mathrm{min}^{-1}$ (day 84.7); (C) during continuous gas supply at $120 \mathrm{~mL} \cdot \mathrm{min}^{-1}$; (D) intermittent gas supply at HRT 2 days (day 140.8); (E) intermittent gas supply at HRT 1 day (day 171.7); and (F) without gas supply (day 219); Figure S3: Carboxylates concentrations over operation time; Figure S4: Inoculum composition at genus level. Taxonomy was assigned based on SILVA 138 SSU Ref NR 99 database.

Author Contributions: Conceptualization, D.P.B.T.B.S.; funding acquisition, C.A.C.-D. and D.P.B.T.B.S.; investigation, C.A.C.-D. and A.A.; methodology, C.A.C.-D. and D.P.B.T.B.S.; supervision, D.P.B.T.B.S.; writing-original draft, C.A.C.-D.; writing—review and editing, C.A.C.-D., C.J.N.B., and D.P.B.T.B.S. All authors have read and agreed to the published version of the manuscript.

Funding: This work was supported by the joint trust fund CONACYT-SENER Sustentabilidad Energética, Mexico (grant number 297027).

Institutional Review Board Statement: Not applicable. 


\section{Informed Consent Statement: Not applicable.}

Data Availability Statement: The datasets generated during the current study are available in the 4TU.ResearchData repository (https: / / doi.org/10.4121/14208530.v1, accessed on 19 March 2021). 16S rRNA gene raw sequences are deposited in the ENA database (https://www.ebi.ac.uk/ena, accessed on 19 March 2021) under the accession number PRJEB43372.

Conflicts of Interest: The authors declare no conflict of interest. The funders had no role in the design of the study; in the collection, analyses, or interpretation of data; in the writing of the manuscript; or in the decision to publish the results.

\section{References}

1. Angenent, L.T.; Richter, H.; Buckel, W.; Spirito, C.M.; Steinbusch, K.J.J.; Plugge, C.M.; Strik, D.P.B.T.B.; Grootscholten, T.I.M.; Buisman, C.J.N.; Hamelers, H.V.M. Chain Elongation with Reactor Microbiomes: Open-Culture Biotechnology to Produce Biochemicals. Environ. Sci. Technol. 2016, 50, 2796-2810. [CrossRef]

2. Sun, Z.; Ramsay, J.A.; Guay, M.; Ramsay, B.A. Carbon-limited fed-batch production of medium-chain-length polyhydroxyalkanoates from nonanoic acid by Pseudomonas putida KT2440. Appl. Microbiol. Biotechnol. 2007, 74, 69-77. [CrossRef]

3. Costa, S.; Summa, D.; Semeraro, B.; Zappaterra, F.; Rugiero, I.; Tamburini, E. Fermentation as a Strategy for Bio-Transforming Waste into Resources: Lactic Acid Production from Agri-Food Residues. Fermentation 2021, 7, 3. [CrossRef]

4. Contreras-Dávila, C.A.; Carrión, V.J.; Vonk, V.R.; Buisman, C.N.J.; Strik, D.P.B.T.B. Consecutive lactate formation and chain elongation to reduce exogenous chemicals input in repeated-batch food waste fermentation. Water Res. 2020, 169, 1-10. [CrossRef]

5. Kim, M.-S.; Na, J.-G.; Lee, M.-K.; Ryu, H.; Chang, Y.-K.; Triolo, J.M.; Yun, Y.-M.; Kim, D.-H. More value from food waste: Lactic acid and biogas recovery. Water Res. 2016, 96, 208-216. [CrossRef] [PubMed]

6. Candry, P.; Radić, L.; Favere, J.; Carvajal-Arroyo, J.M.; Rabaey, K.; Ganigué, R. Mildly acidic pH selects for chain elongation to caproic acid over alternative pathways during lactic acid fermentation. Water Res. 2020, 186. [CrossRef] [PubMed]

7. Zhu, X.; Tao, Y.; Liang, C.; Li, X.; Wei, N.; Zhang, W.; Zhou, Y.; Yang, Y.; Bo, T. The synthesis of n-caproate from lactate: A new efficient process for medium-chain carboxylates production. Sci. Rep. 2015, 5, 1-9. [CrossRef]

8. Kucek, L.A.; Nguyen, M.; Angenent, L.T. Conversion of L-lactate into n-caproate by a continuously fed reactor microbiome. Water Res. 2016, 93, 163-171. [CrossRef] [PubMed]

9. Seeliger, S.; Janssen, P.H.; Schink, B. Energetics and kinetics of lactate fermentation to acetate and propionate via methylmalonylCoA or acrylyl-CoA. FEMS Microbiol. Lett. 2002, 211, 65-70. [CrossRef]

10. Grootscholten, T.I.M.; Steinbusch, K.J.J.; Hamelers, H.V.M.; Buisman, C.J.N. High rate heptanoate production from propionate and ethanol using chain elongation. Bioresour. Technol. 2013, 136, 715-718. [CrossRef]

11. Carvajal-Arroyo, J.M.; Candry, P.; Andersen, S.J.; Props, R.; Seviour, T.; Ganigué, R.; Rabaey, K. Granular fermentation enables high rate caproic acid production from solid-free thin stillage. Green Chem. 2019, 21, 1330-1339. [CrossRef]

12. Roghair, M.; Hoogstad, T.; Strik, D.P.B.T.B.; Plugge, C.M.; Timmers, P.H.A.; Weusthuis, R.A.; Bruins, M.E.; Buisman, C.J.N. Controlling Ethanol Use in Chain Elongation by CO2 Loading Rate. Environ. Sci. Technol. 2018, 52, 1496-1505. [CrossRef] [PubMed]

13. Steinbusch, K.J.J.; Hamelers, H.V.M.; Plugge, M.; Buisman, C.J.N. Biological formation of caproate and caprylate from acetate: Fuel and chemical production from low grade biomass. Energy Environ. Sci. 2011, 4, 216-224. [CrossRef]

14. Wu, Q.; Guo, W.; You, S.; Bao, X.; Luo, H.; Wang, H.; Ren, N. Concentrating lactate-carbon flow on medium chain carboxylic acids production by hydrogen supply. Bioresour. Technol. 2019, 291. [CrossRef]

15. Noorman, H.J.; Van Winden, W.; Heijnen, J.J.; Van Der Lans, R.G.J.M. Intensified Fermentation Processes and Equipment. In Intensification of Biobased Processes; Górak, A., Stankiewicz, A., Eds.; The Royal Society of Chemistry: Cambridge, UK, 2018; pp. 1-41. ISBN 9781782624127.

16. EFSA (European Food Safety Authority). Evaluation of the application for a new alternative processing method for animal by-products of Category 3 material (ChainCraft B.V.). EFSA J. 2018, 16. [CrossRef]

17. Wu, J.; Zhou, H.; Li, H.; Zhang, P.; Jiang, J. Impacts of hydrodynamic shear force on nucleation of flocculent sludge in anaerobic reactor. Water Res. 2009, 43, 3029-3036. [CrossRef]

18. Tay, H.; Liu, S. The effects of shear force on the formation, structure and metabolism of aerobic granules. Appl. Microbiol. Biotechnol. 2001, 57, 227-233. [CrossRef]

19. Roghair, M.; Strik, D.P.B.T.B.; Steinbusch, K.J.J.; Weusthuis, R.A.; Bruins, M.E.; Buisman, C.J.N. Granular sludge formation and characterization in a chain elongation process. Process Biochem. 2016, 51, 1594-1598. [CrossRef]

20. Wu, Q.; Feng, X.; Guo, W.; Bao, X.; Ren, N. Long-term medium chain carboxylic acids production from liquor-making wastewater: Parameters optimization and toxicity mitigation. Chem. Eng. J. 2020, 388, 124218. [CrossRef]

21. Sudmalis, D.; Gagliano, M.C.; Pei, R.; Grolle, K.; Plugge, C.M.; Rijnaarts, H.H.M.; Zeeman, G.; Temmink, H. Fast anaerobic sludge granulation at elevated salinity. Water Res. 2018, 128, 293-303. [CrossRef]

22. Gagliano, M.C.; Sudmalis, D.; Pei, R.; Temmink, H.; Plugge, C.M. Microbial Community Drivers in Anaerobic Granulation at High Salinity. Front. Microbiol. 2020, 11, 1-15. [CrossRef] 
23. Wang, H.; Li, X.; Wang, Y.; Tao, Y.; Lu, S.; Zhu, X.; Li, D. Improvement of n-caproic acid production with Ruminococcaceae bacterium CPB6: Selection of electron acceptors and carbon sources and optimization of the culture medium. Microb. Cell Fact. 2018, 17, 1-9. [CrossRef]

24. Spirito, C.M.; Marzilli, A.M.; Angenent, L.T. Higher Substrate Ratios of Ethanol to Acetate Steered Chain Elongation toward n-Caprylate in a Bioreactor with Product Extraction. Environ. Sci. Technol. 2018, 52, 13438-13447. [CrossRef]

25. Roghair, M.; Liu, Y.; Strik, D.P.B.T.B.; Weusthuis, R.A.; Bruins, M.E.; Buisman, C.J.N. Development of an Effective Chain Elongation Process from Acidified Food Waste and Ethanol Into n-Caproate. Front. Bioeng. Biotechnol. 2018, 6, 1-11. [CrossRef] [PubMed]

26. Kleerebezem, R.; Van Loosdrecht, M.C.M. A generalized method for thermodynamic state analysis of environmental systems. Crit. Rev. Environ. Sci. Technol. 2010, 40, 1-54. [CrossRef]

27. Takahashi, S.; Tomita, J.; Nishioka, K.; Hisada, T.; Nishijima, M. Development of a Prokaryotic Universal Primer for Simultaneous Analysis of Bacteria and Archea Using Next-Generation Sequencing. PLoS ONE 2014, 9. [CrossRef]

28. Klindworth, A.; Pruesse, E.; Schweer, T.; Peplies, J.; Quast, C.; Horn, M.; Glöckner, F.O. Evaluation of general 16S ribosomal RNA gene PCR primers for classical and next-generation sequencing-based diversity studies. Nucleic Acids Res. 2013, 41, 1-11. [CrossRef] [PubMed]

29. Callahan, B.J.; Mcmurdie, P.J.; Rosen, M.J.; Han, A.W.; Johnson, A.J.A.; Holmes, S.P. DADA2: High-resolution sample inference from Illumina amplicon data. Nat. Methods 2016, 13, 581-583. [CrossRef]

30. Quast, C.; Pruesse, E.; Yilmaz, P.; Gerken, J.; Schweer, T.; Glo, F.O.; Yarza, P. The SILVA ribosomal RNA gene database project: Improved data processing and web-based tools. Nucleic Acids Res. 2013, 41, 590-596. [CrossRef]

31. Balcome, S.; Carlson, M. InteractiveDisplay: Package for Enabling Powerful Shiny Web Displays of Bioconductor Objects. 2020. Available online: http://bioconductor.org/packages/release/bioc/html/interactiveDisplay.html (accessed on 19 January 2021).

32. Paulson, J.N.; Stine, O.C.; Bravo, H.C.; Pop, M. Differential abundance analysis for microbial marker-gene surveys. Nat. Methods 2013, 10, 1200-1202. [CrossRef]

33. Oksanen, J.; Blanchet, F.G.; Friendly, M.; Kindt, R.; Legendre, P.; Mcglinn, D.; Minchin, P.R.; O’hara, R.B.; Simpson, G.L.; Solymos, P.; et al. Vegan: Community Ecology Package. 2019. Available online: https://cran.r-project.org/web/packages/vegan/index. html (accessed on 19 January 2021).

34. Beck, M.W.; Mikryukov, V. ggord: Ordination Plots with ggplot2. 2020. Available online: https://fawda123.github.io/ggord/ (accessed on 19 January 2021).

35. Wickham, H. ggplot2: Elegant Graphics for Data Analysis; Springer: Berlin/Heidelberg, Germany, 2008; ISBN 978-0-387-78170-9.

36. Zhu, X.; Zhou, Y.; Wang, Y.; Wu, T.; Li, X.; Li, D.; Tao, Y. Production of high-concentration n-caproic acid from lactate through fermentation using a newly isolated Ruminococcaceae bacterium CPB6. Biotechnol. Biofuels 2017, 10, 1-12. [CrossRef]

37. Scarborough, M.J.; Lawson, C.E.; Hamilton, J.J.; Donohue, T.J.; Noguera, D.R. Metatranscriptomic and Thermodynamic Insights into Medium-Chain Fatty Acid Production Using an Anaerobic Microbiome. mSystems 2018, 3, 1-21. [CrossRef]

38. Zagrodnik, R.; Duber, A.; Łężyk, M.; Oleskowicz-Popiel, P. Enrichment Versus Bioaugmentation-Microbiological Production of Caproate from Mixed Carbon Sources by Mixed Bacterial Culture and Clostridium kluyveri. Environ. Sci. Technol. 2020, 54, 5864-5873. [CrossRef]

39. Lee, J.; Jang, Y.; Han, M.; Kim, Y.; Lee, Y. Deciphering Clostridium tyrobutyricum Metabolism Based on the Whole-Genome Sequence and Proteome Analyses. MBio 2016, 7, 1-12. [CrossRef]

40. Ingham, S.C.; Hassler, J.R.; Tsai, Y.; Ingham, B.H. Differentiation of lactate-fermenting, gas-producing Clostridium spp. isolated from milk. Int. J. Food Microbiol. 1998, 43, 173-183. [CrossRef]

41. Weimer, P.J.; Moen, G.N. Quantitative analysis of growth and volatile fatty acid production by the anaerobic ruminal bacterium Megasphaera elsdenii T81. Appl. Microbiol. Biotechnol. 2013, 97, 4075-4081. [CrossRef]

42. Diez-Gonzalez, F.; Russell, J.B.; Hunter, J.B. The role of an NAD-independent lactate dehydrogenase and acetate in the utilization of lactate by Clostridium acetobutylicum strain P262. Arch. Microbiol. 1995, 164, 36-42. [CrossRef]

43. Tomlinson, N.; Barker, H.A. Carbon dioxide and acetate utilization by clostridium kluyveri. I. Influence of nutritional conditions on utilization patterns. J. Biol. Chem. 1954, 209, 585-595. [CrossRef] [PubMed]

44. Schink, B. Energetics of syntrophic cooperation in methanogenic degradation. Microbiol. Mol. Biol. Rev. 1997, 61, 262-280. [CrossRef] [PubMed]

45. Nzeteu, C.O.; Trego, A.C.; Abram, F.; Flaherty, V.O. Reproducible, high-Yielding, biological caproate production from food waste using a single-phase anaerobic reactor system. Biotechnol. Biofuels 2018, 1-14. [CrossRef]

46. Godwin, S.; Kang, A.; Gulino, L.-M.; Manefield, M.; Gutierrez-Zamora, M.-L.; Kienzle, M.; Ouwerkerk, D.; Dawson, K.; Klieve, A.V. Investigation of the microbial metabolism of carbon dioxide and hydrogen in the kangaroo foregut by stable isotope probing. ISME J. 2014, 8, 1855-1865. [CrossRef] [PubMed]

47. Poehlein, A.; Bremekamp, R.; Lutz, V.T.; Schulz, L.M.; Daniel, R. Draft Genome Sequence of the Butanoic Acid-Producing Bacterium Clostridium luticellarii DSM 29923, Used for Strong Aromatic Chinese Liquor Production. Genome Announc. 2018, 6. [CrossRef] [PubMed]

48. Weghoff, M.C.; Bertsch, J.; Müller, V. A novel mode of lactate metabolism in strictly anaerobic bacteria. Environ. Microbiol. 2015, 17, 670-677. [CrossRef] [PubMed] 